\title{
POLítica de fORMAÇÃo PARA PROfESSORES do ENSINO SUPERIOR E QUALIDADE DE ENSINO: UM ESTUDO SOBRE O PROGRAMA PEDAGOGIA UNIVERSITÁRIA COMO POSSIBILIDADE DE QUALIFICAÇÃO DOCENTE NA PERSPECTIVA PEDAGÓGICO-DIDÁTICA
}

\author{
POLICY TRAINING TEACHERS OF HIGHER EDUCATION AND TRAINING QUALITY: A \\ STUDY ON THE PEDAGOGY UNIVERSITY PROGRAM AS QUALIFYING THE POSSIBILITY \\ OF TEACHERS IN EDUCATIONAL-TEACHING PERSPECTIVE
}
POLÍTICA DE FORMACIÓN PARA PROFESORES DE LA ENSEÑANZA SUPERIOR Y CALIDAD DE LA ENSEÑANZA: UN ESTUDIO SOBRE EL PROGRAMA PEDAGOGÍA UNIVERSITARIA COMO POSIBILIDAD DE CALIFICACIÓN DOCENTE EN LA PERSPECTIVA PEDAGÓGICO-DIDÁTICA

\section{Isabel Cristina de Almeida Mantovani ${ }^{1}$ Silvia Regina Canan ${ }^{2}$}

\section{RESUMO}

As reflexões presentes neste artigo têm por tema as políticas de formação pedagógico-didáticas para professores do ensino superior e qualidade do ensino e resultam de uma pesquisa desenvolvida numa Universidade Comunitária do Interior do Rio Grande do Sul, envolvendo docentes-bacharéis que procurou responder: "É possível estabelecer relações entre a ausência de formação pedagógico-didática dos docentes e de políticas definidoras dessa formação e a qualidade do ensino, no Ensino Superior?" Para responder a questão de pesquisa, procurou-se investigar se o programa pedagogia universitária, desenvolvido em serviço pode ser considerado como espaço que supre a falta de formação pedagógico-didática, e se representa um fator positivo no que se refere à possibilidade de suprir a deficiência nesse campo.

PALAVRAS-CHAVE: Docência universitária. Formação continuada. Políticas públicas.

\section{ABSTRACT}

The reflections presented in this article are by theme pedagogical-didactic training policies for higher education teachers and quality of education and result of a research developed a Community University interior of Rio Grande do Sul, involving teachers, graduates who sought to answer : "You can establish relationships between the absence of pedagogical-didactic training of teachers and defining policies of training and the quality of teaching in higher education" To answer the research question, we sought to investigate whether the university pedagogy program, service developed can be considered as a space, which meets the lack of didacticeducational training, and is a positive factor as regards the possibility to supply the deficiency in this field.

KEYWORDS: University teaching. Continuing training. Public policy.

\section{RESUMEN}

Las reflexiones presentadas en este artículo tienen por tema las políticas de formación pedagógico-didácticas para profesores de la enseñanza superior y calidad de la enseñanza, resultante de investigación desarrollada en una Universidad Comunitaria del interior de Rio Grande do Sul, involucrando docentes-licenciados que buscó

\footnotetext{
${ }^{1}$ Mestre em Educação pela Universidade Regional Integrada do Alto Uruguai e das Missões; Doutoranda em Ciências da Educação. Pesquisadora convidada da Universidade Federal do Pampa. E-mail: isabel.cristina1@hotmail.com

${ }^{2}$ Mestre em Educação pela Universidade Federal do Rio Grande do Sul e Doutora em Educação pela

UNISINOS. Professora da Universidade Regional Integrada do Alto Uruguai e das Missões - Câmpus de

Frederico Westphalen. E-mail: silvia@uri.edu.br

Recebido em: 27/09/2015 - Aceito em: 03/12/2015.

\begin{tabular}{l|l|l|l|l|l|l} 
(C) Rev. Inter. Educ. Sup. & Campinas, SP & v.1 & n.2 & p.136-148 & out./dez. 2015 & ISSN 2446-9424 \\
\hline
\end{tabular}
}


contestar: “¿Es posible establecer relaciones entre la ausencia de formación pedagógico-didáctica de los docentes y de políticas definidoras de esa formación y la calidad de la enseñanza Superior?" Para responder al interrogante, se buscó saber si el programa pedagogía universitaria, desarrollado en servicio, podría ser considerado como espacio que suple la falta de formación pedagógico-didáctica, y si representa un factor positivo en lo que se refiere a la posibilidad de suplir la deficiencia en ese campo.

PALABRAS-CLAVE: Docencia universitaria. Formación continuada. Políticas públicas.

\section{INTRODUÇÃO}

A educação tem sido vista, especialmente pelos meios de comunicação, como um dos grandes problemas do país. Os próprios educadores não discordam e endossam as críticas à qualidade e às deficiências. Mas, de outro lado, os investimentos vêm sendo grandes. Nunca houve tantas universidades, instituições de ensino superior e, portanto, tantas vagas em oferta bem como, nunca se teve tantos mecanismos quanto agora para democratizar o acesso da população a todos os níveis da educação. E, ainda assim, percebe-se que os resultados não evoluíram, suficientemente, em relação à qualidade do ensino.

As deficiências de formação dos professores, muitas vezes, estão entre as críticas apontadas e entre as causas consideradas quando se trata de avaliar o porquê da qualidade do ensino ser deficiente. Todavia, nossos professores têm maior preparação em relação ao que ocorria há algumas décadas. Nunca tivemos tantos mestres e doutores em sala de aula, muitas vezes profissionais consagrados no mercado e com um vasto conhecimento sobre a disciplina que estão ensinando.

Então, por que subsistem as críticas à qualidade da educação? Porque, como se verifica em relatos e até mesmo pelas avaliações de educadores experientes, que alguns professores não têm o conhecimento pedagógico-didático, necessários para trabalhar com seus alunos os conhecimentos que detêm. Podemos arriscar dizendo que, grande parte deles não foram ensinados ou preparados para ensinar?

Das inúmeras alterações ocorridas no final do século $\mathrm{XX}$, no cenário da Educação Superior, decorrentes principalmente das exigências postas pela UNESCO em 1998 e reafirmadas em 2003, respectivamente através da Declaração Mundial da Educação Superior para o século XXI e do documento Educação Superior: reforma, mudança e internacionalização, o movimento de atenção à mediação didática por parte da docência universitária tem vindo a ampliar-se e a indiciar um lugar para o conhecimento didático pedagógico - apesar deste conhecimento ainda estar longe de superar a condição de relegado a um plano secundário na relação com o conhecimento da área de atuação específica.

Nesse contexto, uma crescente procura por ações de formação continuada na área pedagógico-didática e de mobilização institucional para viabilizar a oferta de ações desta ordem, tem vindo a justificar o investimento em programas de desenvolvimento profissional ao docente universitário, com vistas à melhoria da qualidade do ensino superior no Brasil. Fato que vem ratificando a pertinência de uma reflexão sobre contribuições de ações de

\begin{tabular}{l|l|l|l|l|l|l} 
(C) Rev. Inter. Educ. Sup. & Campinas, SP & v.1 & n.2 & p.136-148 & out./dez. 2015 & ISSN 2446-9424
\end{tabular}


formação continuada no processo de reconhecimento de um lugar para o conhecimento pedagógico-didático na docência universitária - principalmente diante da participação de docentes que atuam em campos que tradicionalmente se pautam pela racionalidade técnica, no que se refere ao conhecimento a ser compreendido como acabado e neutro (CUNHA, 1998).

Segundo Zabalza (2004), talvez não haja dúvida nenhuma de que a peça fundamental no desenvolvimento da docência na educação superior sejam os professores. Sendo as instituições de educação superior "unidades formativas", ninguém deveria desprezar nem o papel dessa função primordial, nem a importância daqueles que a exercem. Muito embora exista consenso em torno dessa afirmação, a legislação brasileira é omissa quando se trata da formação pedagógico-didática para os docentes, com formação em bacharelado.

Como é sabido, para ministrar aulas nos cursos de graduação não há qualquer exigência ou diretriz quanto à necessidade da formação para a docência, a não ser a preferência pelo stricto sensu. Para ser professor neste nível de ensino, basta ter, além do curso de graduação, um curso de Pós-graduação (Especialização, Mestrado ou Doutorado), preferencialmente em sua área de formação.

Ao remeter às Universidades, e aos programas de pós-graduação, a responsabilidade pela formação pedagógico-didática dos docentes sem determinar um currículo mínimo para tanto, percebe-se uma omissão. Essa omissão permite aquilo que se observa na prática, que é o preparo de profissionais voltados mais para a pesquisa do que para a docência. Esse fato, aliado ao critério mínimo exigido pelo Ministério da Educação - MEC, para habilitação ao acesso de profissionais à docência no Ensino Superior, de possuir apenas um curso de pósgraduação, leva um contingente cada vez maior de profissionais bacharéis a atuar sem o preparo em questões pedagógico-didáticas, apesar da existência de um instrumento de avaliação institucional, que exija uma formação que vá além dessa.

A discussão sobre a criação de um novo sistema de avaliação da educação superior teve o seu início em abril de 2003, quando foi criada a Comissão Especial de Avaliação CEA que, após realizar discussões com a comunidade acadêmica e com a sociedade civil organizada, produziu o documento intitulado "SINAES: bases para uma nova proposta de avaliação da educação superior" (BRASIL, 2004).

O Sistema Nacional de Avaliação do Ensino Superior - SINAES, criado pela Lei $\mathrm{n}^{\circ}$ 10.861/2004, surge com objetivos de identificar o mérito e valor das instituições, áreas, cursos e programas nas dimensões de ensino, pesquisa, extensão, gestão e formação; melhorar a qualidade da educação superior, orientar a expansão da oferta de cursos e promover a responsabilidade social das Instituições de Ensino Superior, respeitando a identidade institucional e a sua autonomia (BRASIL, 2004).

Neste trabalho, cujo foco são as políticas públicas, a formação docente e qualidade de

\begin{tabular}{l|l|l|l|l|l|l} 
(c) Rev. Inter. Educ. Sup. & Campinas, SP & v.1 & n.2 & p.136-148 & out./dez. 2015 & ISSN 2446-9424
\end{tabular}


ensino no que se refere à avaliação institucional externa abordou-se apenas à dimensão cinco da avaliação externa, que avalia: as políticas de pessoal, de carreiras do corpo docente [...] seu aperfeiçoamento, e seu desenvolvimento profissional [...]. Com esta normatização, as Instituições de Ensino Superior se viram obrigadas a instituir programas de qualificação continuada em serviço para suprir as deficiências na formação pedagógico-didáticas de seus docentes e para promover a formação continuada e, em consequência, melhorar a qualidade do ensino.

Essa dimensão foi o parâmetro utilizado, neste estudo, para conceituar qualidade, uma vez que a subjetividade do termo exigiu que se tivesse uma referência sobre a qual fosse possível fundamentá-la. O problema a ser investigado, questionou: "É possível estabelecer relações entre a ausência de formação pedagógico-didática dos docentes e de políticas definidoras dessa formação e a qualidade do ensino, no Ensino Superior?" Daí decorreu o objetivo principal que procurou investigar se o programa pedagogia universitária, desenvolvido em serviço numa Universidade do interior do estado do RS, envolvendo os docentes bacharéis do Departamento de Engenharia, Ciências Agrárias e Arquitetura, pode ser considerado como espaço que supre a falta de formação pedagógico-didática, representando um fator positivo no que se refere a possibilidade de suprir a deficiência nesse campo.

Muitos são os desafios que se impõem à educação superior, sendo este um campo que demanda investigações interdisciplinares, especialmente quando se trata de políticas públicas para este nível de ensino. A formação dos docentes que atuam no Ensino Superior apresentase como uma preocupação atual, já que estes têm demonstrado em suas práticas uma falta de preparo para formar profissionais. Para dar conta dessas questões, procurou-se avaliar o que ainda apresenta-se como um dos problemas, a formação dos professores bacharéis, e sua condição para desenvolverem uma educação de qualidade, partindo-se do pressuposto de que eles podem não estar ensinando bem. E, se isso ocorre, quais são as causas, sejam as relacionadas à formação ou à legislação. $\mathrm{O}$ objetivo foi entender melhor uma vasta gama de aspectos através da pesquisa, que envolvem, especialmente, Políticas de Formação Pedagógico-Didática para Professores do Ensino Superior e Qualidade de Ensino.

A pesquisa desenvolveu-se a partir de um programa de qualificação em serviço, implantado na Universidade pesquisada e analisando o programa de formação continuada, a fim de compreender se ele pode ser considerado como espaço que supere a falta de formação pedagógico-didática, representando um fator positivo no que se refere à possibilidade de suprir deficiências dos professores bacharéis que atuam no Ensino Superior.

Fica explícito que se exige o conhecimento, mas não se avalia a capacitação do profissional para tornar acessível e eficiente o compartilhamento desse conhecimento com os alunos. Ele conhece, mas nem sempre, sabe contribuir com a construção do conhecimento pelos seus alunos De quem deve ser esse compromisso? Das instituições? Do próprio professor? Das políticas públicas que regem o Ensino Superior?

\begin{tabular}{l|l|l|l|l|l|l} 
(C) Rev. Inter. Educ. Sup. & Campinas, SP & v.1 & n.2 & p.136-148 & out./dez. 2015 & ISSN 2446-9424 \\
\hline
\end{tabular}




\section{A LEI DE DIRETRIZES E BASES DA EDUCAÇÃO NACIONAL E AS OPINIÕES SOBRE FORMAÇÃO DOCENTE}

A Lei de Diretrizes e Bases da Educação Nacional (LDB), n. 9.394/96, definiu, no Art. 66, que "A preparação para o exercício do magistério superior far-se-á em nível de pósgraduação, prioritariamente em programas de mestrado e doutorado". Não obstante nos cursos de pós-graduação existir disciplinas de formação pedagógica, constantes do programa de cada curso, essas disciplinas não dão conta do preparo específico para a docência, uma vez que estes cursos estão muito mais focados no desenvolvimento do conhecimento e do preparo de pesquisadores.

Importante citar que a Lei de Diretrizes e Bases (LDB), em seu artigo 65, prevê que "a formação docente, exceto para a educação superior, incluirá prática de ensino de, no mínimo, trezentas horas". Um número de horas de efetiva docência para a educação superior não melhoraria e prepararia melhor nossos professores? Diante desta realidade, acaba-se transferindo para as Instituições de Ensino Superior a tarefa da formação dos professores, sob forma de educação continuada em serviço. Em decorrência disso, observa-se, na atualidade, uma lacuna importante na formação didático-pedagógica, pois os professores que atuam nas Instituições de Ensino Superior, principalmente nas áreas tecnológicas, não têm recebido a formação adequada e sofrem por essa falta, podendo sofrer com prejuízos para si e para os estudantes.

Referindo-se às estruturas curriculares dos cursos de graduação em engenharia, observa-se que essas também não apresentam componentes curriculares que preparam os futuros engenheiros em questões pedagógicas, qualificando, dessa forma, para a docência. Para ser professor no ensino superior basta ter, além do curso de graduação, um curso de pósgraduação (especialização, mestrado ou doutorado) em qualquer área.

Em se tratando do Ensino Superior, a docência emerge como uma questão intrigante, principalmente quando se trata de formar professores para atuar neste nível de ensino, uma vez que a legislação precisa estabelecer diretrizes específicas. Para isto, de acordo com Morosini (2000), a formação do docente para atuar no ensino superior tem sido considerada obscura, tendo em vista que a legislação não esclarece de que forma deverá se organizar essa formação. Para a autora, a principal característica dessa legislação sobre quem é o professor universitário, no âmbito de sua formação didática, é o silêncio.

Para Cunha (1998), o processo de aprendizagem que ocorre na educação superior tem sido utilizado apenas como um estudo de validação e produção do conhecimento científico, cujas decisões deveriam parecer estritamente pedagógicas e estar agregadas às decisões sobre as formas de organização e distribuição do conhecimento realizado na sociedade. Muito comum essas decisões não serem evidenciadas na compreensão do professor universitário, pois isso nem tem sido objeto de investigações sistemáticas. Grande parte dos estudos está voltada unicamente para a universidade, para a perspectiva histórico-política ou ao estritamente didático. Para a autora, o professor deve ser tratado "como articulador por excelência do paradigma de ensinar e de aprender na universidade, e daí a importância de estudar sua prática e sua formação" (p.15).

Segundo Masetto (2001), principalmente no ensino da engenharia, existe pouca ou

\begin{tabular}{l|l|l|l|l|l|l} 
() Rev. Inter. Educ. Sup. & Campinas, SP & v.1 & n.2 & p.136-148 & out./dez. 2015 & ISSN 2446-9424
\end{tabular}


nenhuma preocupação com a formação pedagógica do professor, o que leva o docente a continuar repetindo velhos modelos, assim sendo mero transmissor de informações, não preparando os alunos a pensarem por si próprios, enfrentarem desafios ou resolverem problemas com criticidade. Elementos esses necessários aos profissionais das engenharias que são exigidos pelo mundo moderno. Segundo o pensador, no contexto da aprendizagem, o foco está no aluno e não no professor. Nas discussões envolvendo o ensino de engenharia, fala-se muito de renovação pedagógica como uma necessidade crescente para se vencer os desafios da sociedade em que vivemos. Essa discussão, normalmente, está desvinculada da questão sobre a formação dos formadores de engenheiros.

No entendimento de Pimenta e Anastasiou (2002, p. 37), na maioria das Instituições de Ensino Superior, embora seus professores possuam experiência significativa e mesmo anos de estudos em suas áreas específicas, predomina o despreparo e até um desconhecimento científico do que seja o processo de ensino-aprendizagem, pelo qual possam ser responsáveis a partir do instante em que ingressam na sala de aula "[...] não recebem qualquer orientação sobre processo de planejamento, metodológico ou avaliatório, não têm de prestar contas, fazer relatórios, como acontece normalmente nos processos de pesquisa - estes, sim, objeto de preocupação e controle institucional" (PIMENTA e ANASTASIOU, 2002, p.37).

Segundo Masetto (2009), é importante repensar a formação do professor de ensino superior, pois as Diretrizes Curriculares atuais aprovadas pelo Ministério da Educação para todos os cursos de graduação do ensino superior oferecem abertura nesse sentido. Os currículos mínimos foram substituídos por explicitação de um conjunto de competências, hoje, fundamentais para cada perfil profissional. Essas competências procuram abranger aspectos de construção de conhecimento, de pesquisa, de abertura para outras áreas de conhecimento para além de sua especificidade, de abertura para inovações, de trabalho em equipe multi e interdisciplinar e outras mais específicas para cada uma das profissões, conforme as discussões existentes na área.

Importante ressaltar que até pouco tempo o ensino superior foi considerado como ponto terminal da educação e voltado à formação profissional, e a partir de agora assume outras funções, como, por exemplo, a educação permanente, um fenômeno que vem acontecendo não só no Brasil. Estas preocupações nos levam a refletir sobre a formação dos professores para atuar no ensino superior e que nos remetem aos questionamentos propostos por Morosini (2000, p.1): “quem são (serão) esses novos professores? Estamos preparados didaticamente?".

A percepção por parte de pesquisadores, profissionais da área da educação, aponta para a necessidade de um maior preparo dos professores para a prática docente no ensino superior, e a área das engenharias está inserida neste contexto. Considerando tudo que foi exposto até aqui, pode-se dizer que a realidade aponta para a necessidade urgente de formação pedagógica dos professores, podendo até vir a se constituir numa exigência do sistema educacional. Como concluem Benedito, Ferrer e Ferreres (1995), "a docência universitária é importante e a formação de seus profissionais já não admite demora" (p.186187).

Considerando ainda, que a diferença de tratamento que é dado pela legislação com relação à efetiva formação de professores nos diferentes níveis, educação básica e ensino

\begin{tabular}{l|l|l|l|l|l|l} 
(C) Rev. Inter. Educ. Sup. & Campinas, SP & v.1 & n.2 & p.136-148 & out./dez. 2015 & ISSN 2446-9424
\end{tabular}


superior, parece afrontar o senso comum. A legislação, que explicita de maneira contundente os requisitos para atuação no ensino básico, apresenta-se de maneira extremamente aberta para a atuação dos profissionais docentes no ensino superior. Essa diferenciação na atribuição de requisitos para atuação nos diferentes níveis de ensino no mínimo é capaz de suscitar a dúvida de que a quase inexistência de exigência para atuação no ensino superior pode estar causando uma perda da qualidade de ensino, justo em um momento em que há uma expansão do ensino superior no Brasil.

Neste estágio de desenvolvimento da educação formal no país, aonde um sistema de avaliação vem sendo implementado no qual ninguém é deixado de lado, instituições, docentes, discentes e demais partícipes da comunidade acadêmica, é incompreensível que, passados cerca de dezessete anos da promulgação da LDB, continuemos silenciando a respeito de políticas públicas relacionadas à formação de professores para atuação no ensino superior.

A última reforma universitária ocorreu no ano de 1968 e há dez anos se está discutindo uma nova reforma sem previsão de conclusão. A sensação que se tem é de que está tudo bem, entretanto, essa não parece ser a realidade. A qualidade do ensino está vinculada de maneira direta à atuação do professor e se isso é um fato, como melhorar a qualidade, se professores continuam chegando para atuar no Ensino Superior sem formação adequada para tanto? Essa é uma questão chave que precisa de uma solução que passa também por uma legislação que não silencie, mas que proporcione ferramentas que definam a implantação efetiva de políticas públicas referentes à formação dos docentes para atuação no Ensino Superior.

\section{METODOLOGIA}

A pesquisa, conforme Ander-Egg (1978, p. 28) "é um procedimento reflexivo sistemático, controlado e crítico, que permite descobrir novos fatos e dados, relações ou leis, em qualquer campo do conhecimento". A pesquisa, portanto, é um procedimento formal, com método de pensamento reflexivo, que requer um tratamento científico e se constitui no caminho para conhecer a realidade ou para descobrir verdades parciais.

Como a pesquisa científica requer um procedimento formal, é importante a definição de uma metodologia adequada, buscou-se, através da pesquisa, responder a seguinte indagação: É possível estabelecer relações entre a ausência de formação pedagógico-didática dos docentes e de políticas definidoras dessa formação e a qualidade de ensino, no Ensino Superior? A questão em foco levou à busca respostas para uma lacuna importante no processo formativo do Ensino Superior no Brasil.

A pesquisa desenvolvida teve enfoque quali-quantitativo, desenvolvida através de um estudo de caso, tendo na dialética a inspiração para análise dos dados coletados através de questionários e entrevistas com docentes e coordenadores do Departamento de Engenharia, Arquitetura e Ciências Agrárias, de uma Universidade Comunitária do interior do Estado do Rio Grande do Sul, totalizando 63 sujeitos convidados. Quanto aos meios de investigação, a pesquisa qualifica-se como bibliográfica e de campo. Gamboa, (1987) aponta a dialética

\begin{tabular}{l|l|l|l|l|l|l} 
(C) Rev. Inter. Educ. Sup. & Campinas, SP & v.1 & n.2 & p.136-148 & out./dez. 2015 & ISSN 2446-9424
\end{tabular}


como método apropriado, que aproxima o investigado do entendimento crítico, trazido pelo confronto do concreto, da inter-relação, do todo e das partes.

A escolha pela instituição pesquisada e pela área justiça-se, pois, essa Universidade possui um diferencial na qualificação de seu corpo docente, realizada em serviço (formação continuada), na qual se retrata a realidade de forma completa e profunda, na expectativa de mostrar esta experiência como possibilidade de melhoria na qualidade de ensino, buscando, de certa forma, aprimorar a qualificação pedagógico- didática, praticamente inexistente na formação inicial do grupo docente.

\section{RESULTADOS E DISCUSSÕES}

Os achados da pesquisa permitiram uma aproximação com a realidade vivenciada pelos docentes-bacharéis pesquisados. Os conhecimentos prévios sobre a instituição e sobre aqueles que nela atuam foram significativamente ampliados, visto que a investigação permitiu a pesquisadora problematizações, analises e interpretações.

Inicialmente apresentamos a caracterização dos sujeitos envolvidos na pesquisa e na sequência, os eixos que contemplam os objetivos da investigação: formação pedagógicodidática; qualidade de ensino e o Programa de Pedagogia Universitária.

\section{Caracterização dos sujeitos}

Todos os docentes e coordenadores do Departamento foram convidados a participar, como respondentes de questionário e de entrevista respectivamente, após serem devidamente esclarecidos a respeito das questões éticas da pesquisa.

Participaram da pesquisa, como respondentes do questionário, quatorze (14) docentes de um total de sessenta e três (63) docentes, correspondendo a uma participação de vinte três por cento $(23 \%)$ dos docentes que atuam no departamento pesquisado da referida instituição.

Com relação aos coordenadores realizaram-se entrevistas como um procedimento de pesquisa qualitativa, através de um roteiro semiestruturado considerando aspectos da formação inicial, de interesse pela docência, do trabalho do professor, do trabalho como coordenador, da avaliação institucional docente, da formação continuada, da qualidade da educação no ensino superior, dos saberes docentes, das políticas públicas de formação docente para os engenheiros, e do programa pedagogia universitária como possibilidade de qualificação docente. Dos oito (8) coordenadores convidados a participara da pesquisa, tivemos a adesão de seis (6) correspondendo a setenta e cinco (75\%) dos sujeitos.

\section{Perfil dos docentes}

- Faixa etária - 50\% na faixa de 28 a 40 anos de idade, $14 \%$ na faixa de 41 a 50 anos de idade e $36 \%$ na faixa de 51 a 60 anos de idade;

- Formação acadêmica - $21 \%$ com doutorado, $72 \%$ com mestrado e $7 \%$ com especialização;

- Tempo de docência no Ensino Superior - 43\% até 5 anos, 36\% entre 6 e 15 anos e 
$21 \%$ entre 16 e 25 anos;

- Tempo de docência na IES - 72\% até 5 anos, $14 \%$ entre 6 e 15 anos e $14 \%$ entre 16 e 25 anos;

- Regime de trabalho - $14 \%$ tempo integral, $22 \%$ tempo parcial e $64 \%$ tempo especial.

\section{Perfil dos coordenadores de curso}

- Faixa etária - 50\% na faixa de 28 a 40 anos de idade, $33 \%$ na faixa de 41 a 50 anos de idade e $17 \%$ na faixa de 51 a 60 anos de idade;

- Formação acadêmica - 33\% com doutorado, 67\% com mestrado;

- Tempo de docência no Ensino Superior - $17 \%$ até 5 anos, 50\% entre 6 e 15 anos e $33 \%$ entre 16 e 25 anos;

- Tempo de docência na IES - 17\% até 5 anos, $50 \%$ entre 6 e 15 anos e $33 \%$ entre 16 e 25 anos;

- Regime de trabalho - $100 \%$ tempo integral.

A partir do perfil apresentado e das respostas aos questionamentos, foi possível chegar a algumas constatações relevantes no que tange à questão norteadora da pesquisa. A IES segue os parâmetros exigidos pelo MEC com relação a exigência mínima de formação do seu quadro docente entretanto, percebe-se que dentre os respondentes, apenas 2, ou seja $10 \%$ admitiram possuir alguma espécie de formação didático-pedagógica. Quanto ao regime de trabalho, concluímos que os coordenadores de curso possuem regime integral, porém somente $17 \%$ dos docentes, goza do mesmo regime. A grande maioria, $64 \%$ possuem tempo especial, ou seja, são contratados como horistas com carga horária variável.

Muito embora, a fala de uma parcela significativa dos entrevistados ressaltasse a importância do conjunto de professores exercer outra atividade profissional paralela, o que contribui para a aproximação da academia à vivência profissional, por outro lado, apontam a dificuldade que esse fato reflete pela falta de vivência e acompanhamento do cotidiano dos seus alunos e da vida acadêmica. Aliado a isso percebe-se uma suposta desobrigação de se participar de atividades de formação continuada e atividades de pesquisa e extensão.

\section{Opção pela docência e a formação pedagógico-didática}

Em relação à motivação para o exercício da docência e a formação pedagógicodidática ressalta-se:

Com relação à exigência de formação para o exercício da docência no Ensino Superior regradas pelo Art. 66 da Lei de Diretrizes e Bases da Educação Nacional, a maioria dos docentes (67\%) acredita ser insuficiente, destacam-se a resposta de dois dos docentes entrevistados:

Em minha opinião, o simples repasse para as universidades, da maneira como foi feito pela LDB, é querer se livrar de um problema, ser omisso. A lei não pode se omitir em um aspecto tão importante e fundamental para a qualidade da educação. $\mathrm{Na}$ minha visão, a Legislação deveria estabelecer requisitos mínimos para a docência em nível superior que contemple a prática e conteúdos compatíveis com o exercício profissional. A docência deve ser encarada como profissão e não como possibilidade pelos cursos de graduação e pós-graduação. Para que isso ocorra, deve ser criado um currículo mínimo para o exercício da docência em qualquer nível, 
para que o futuro docente tenha o preparo mínimo necessário ao exercício profissional. Da mesma maneira, ciclos de reciclagem devem ser previstos e contemplados em lei. (Docente A)

Formação pedagógica é fundamental para preparar um profissional com o mínimo de competências para assumir a função de docente. A formação existente, nestes cursos (Mestrado e Doutorado), não forma a competência mínima necessária para a vida profissional de um professor. Existem inúmeros cursos que auxiliam nesta formação, inclusive de forma EAD. (Docente B).

Evidenciou-se a partir da análise dos relatos apresentados, a existência de uma lacuna, a falta de preparação pedagógico-didática dos participantes da pesquisa. Uma das alternativas encontrada pela IES pesquisada, para minimizar as dificuldades foi o programa de capacitação docente ou de formação continuada, que emerge da política de qualificação da ação pedagógica de apoio aos docentes, e constitui-se como um espaço de estudo e reflexão sobre a docência em sala de aula, possibilitando a construção e reconstrução de conhecimentos relacionados à prática pedagógica, com vistas à melhoria da qualidade de ensino.

\section{Qualidade de ensino}

Em relação a qualidade de ensino verificou-se que 50\% dos participantes avaliaram a qualidade da educação no Brasil como regular, um docente avaliou como ruim, três docentes disseram não ter condições de responder e que observam os resultados do SINAES, outro afirmou que ainda carecemos de mais estrutura e principalmente investimento na qualificação docente. Os coordenadores foram unânimes em afirmar que poderia ser melhor a qualidade do ensino superior no Brasil.

Já com relação à qualidade de ensino ofertado pela IES, obteve-se as seguintes respostas: Instituição em busca de aprimoramento; Boa qualidade, boa estrutura, egressos com habilidades suficientes; Para se inserirem no mercado de trabalho; Importante inserção na comunidade, tem qualidade e credibilidade; Universidade democrática; Em plena luta por atingir a excelência em qualificação. Muito comprometida com a melhoria do ensino no país; Instituição com tradição.

\section{Programa de Pedagogia Universitária}

O programa se constitui como um espaço de estudo e reflexão sobre a docência no ensino superior, no que diz respeito à dinâmica da sala de aula, possibilitando a construção e reconstrução de conhecimento relacionados à prática pedagógica.

A Universidade pesquisada sempre teve a preocupação com a qualificação pedagógica e promove atividades desde 1995. Inicialmente as capacitações eram chamadas Formação Pedagógicas Docentes, mas com a ampliação do número de docentes surgiu a necessidade da criação de um programa que oferecesse além de palestras, outras atividades de qualificação.

$\mathrm{Na}$ ótica dos entrevistados, com relação a capacidade do programa de Pedagogia Universitária respaldar ou não o trabalho pedagógico a quase totalidade afirma que o programa contribui, entretanto poderia ser melhor, a exceção de 3 docentes que não responderam, um que diz não ter condições de opinar e um que diz desconhecer o programa.

\begin{tabular}{l|l|l|l|l|l|l} 
(C) Rev. Inter. Educ. Sup. & Campinas, SP & v.1 & n.2 & p.136-148 & out./dez. 2015 & ISSN 2446-9424 \\
\hline
\end{tabular}




\section{CONCLUSÕES}

A partir da pesquisa, foi possível levantar uma série de desafios a serem enfrentados pelo Programa Pedagogia Universitária da IES investigada quais sejam:

- Investimento maior do ponto de vista financeiro e institucional;

- Sustentar a qualidade de formação e do ensino em bases éticas e de responsabilidade social para que se evite o treinamento culturalista e não inovador;

- Ações desencadeadas institucionalmente caminhando para a ação coletiva e partilhada no desenvolvimento do trabalho pedagógico nas universidades;

- Conscientização dos docentes sobre a necessidade de além de considerarem seus domínios específicos, investirem na dimensão pedagógica da docência;

- Promover amplas discussões sobre as políticas institucionais de valorização nas ações de ensino na graduação;

- A valorização da formação como meio de propiciar um caminho de qualificação do trabalho docente, implica na possibilidade de aproximar as teorias apropriadas da prática exercida;

- Auxiliar o docente nas questões pedagógico-didáticas, levando os mesmos a perceber que em interação com os seus alunos e com base nos conhecimentos já estabelecidos pelas diversas ciências, podem efetivamente produzir, criar e recriar conhecimentos próprios da atividade discente e docente;

- Programa pedagogia universitária é um espaço que pode ser melhor aproveitado, evidenciando, assim, a busca de uma postura reflexiva;

- Compreender que o processo de construção de conhecimento pedagógico compartilhado é tão fundamental, quanto compreender o aprender a aprender, o que equivale a ser capaz de realizar aprendizagens, em diferentes situações e contextos que favoreçam a aquisição de estratégias cognitivas, considerandose as condições individuais de cada sujeito na sua interação com pares;

- As crenças e concepções teóricas implícitas que os professores têm acerca de seu fazer pedagógico podem sinalizar a maneira como eles processam as informações e como percebem as formas de intervenção didática, como marco de referência para sua prática, construindo seu conhecimento pedagógico de forma compartilhada.

A investigação conseguiu responder a questão que esteve na motivação deste estudo: "É possível estabelecer relações entre a ausência de formação pedagógico-didática dos docentes e de políticas definidoras dessa formação e a qualidade do ensino, no Ensino Superior?" Concluímos que o Programa Pedagogia Universitária trata-se de um importante espaço para a formação continuada e na construção de uma prática pedagógica que se traduza em uma educação de qualidade. 
Resta-nos, a partir dos achados deste trabalho suscitar questionamentos que poderiam ser explorados em futuras pesquisas. Dentre eles, destacamos:

- Os indicadores propostos pelo SINAES relacionados à questão da formação docente e formação continuada no Ensino Superior são suficientes para produzir uma melhoria significativa na qualidade do ensino?

- As políticas públicas relacionadas à formação docente e à formação continuada para o Ensino Superior são capazes de responder às demandas que a sociedade moderna espera?

- Ainda persiste o pensamento de dissociação entre pedagogia e saberes específicos? Quais as causas desse pensamento e sua validade no processo de ensino aprendizagem?

\section{REFERÊNCIAS}

ANDER-EGG, Ezequiel. Introduccion a las técnicas de investigacion social: para trabajadoressociales. 7.ed. Buenos Aires: Humanitas, 1978. Parte II, capítulo 6.

\section{ANDRÉ, M. P. et al. (Org.). O papel da pesquisa na formação e na prática dos} professores. Campinas: Papirus, 2001.

BENEDITO, A. V.; FERRER, V.; FERRERES, V. La formación universitaria a debate. Barcelona: Publicaciones Universitat de Barcelona, 1995.

BRASIL. Lei n. 9.394 de 20 de dezembro de 1996. Estabelece as diretrizes e bases da Educação.

BRASIL. Ministério da Educação e Cultura. Lei n. 10.861 de 14 de abril de 2004. Institui o Sistema Nacional de Avaliação do Ensino Superior - SINAES e dá outras providências.

BRZEZINSKI, Iria. Profissão professor: identidade e profissionalização docente. Brasília: Plano Editora, 2002.

CRESWELL, John W. Procedimentos qualitativos. In: PROJETO de pesquisa: métodos qualitativo, quantitativo e misto. 2. ed. Porto Alegre: Artmed, 2007.

CUNHA, Maria Isabel da. O bom professor e sua prática. Campinas, SP: Papirus, 1989.

FONSECA, João José Saraiva. Metodologia da pesquisa científica. Fortaleza: UEC, 2002. Apostila.

MASETTO, Marcos T. Atividades pedagógicas no cotidiano da sala de aula universitária: reflexões e sugestões práticas. In: CASTANHO, Sérgio; CASTANHO, Maria Eugênia (Org.). Temas e textos em metodologia do ensino superior. 1.ed. Campinas,SP: Papirus, 2001. 
MASETTO, Marcos T. Formação continuada de docentes do ensino superior numa sociedade do conhecimento. In: CUNHA, Maria Isabel da; SOARES, Sandra Regina; RIBEIRO,

Marinalva Lopes (Org.). Docência universitária: profissionalização e práticas educativas.

Feira de Santana: UEFS Editora, 2009, v.1, p.99-116.

MOROSINI, Marília Costa.Docência universitária e os desafios da realidade nacional. In:__ (Org.). Professor do ensino superior: identidade, docência e formação. Brasília: Instituto Nacional de Estudos e Pesquisas Educacionais, 2000.

PIMENTA, S. G.; ANASTASIOU, L. G. C. Docência no ensino superior. São Paulo: Cortez, 2002.

RAMALHO, B. L. Reflexões sobre o ensino e o exercício da docência no ensino superior. ForGRAD em revista, Vitória, n.1, p.26-32, 2006.

SANCHEZ GAMBOA, Silvio. Epistemologia da pesquisa educação. 1987. Tese (Doutorado em educação) - Faculdade de Educação, Universidade Estadual de Campinas, Campinas, 1987.

TARDIF, M. Saberes profissionais de professores e conhecimentos universitários: elementos [....] à formação para o magistério. Rev. Bras. de Educ., Rio de Janeiro, n.13, jan./abr. 2000.

ZABALZA, M. A.O ensino universitário: seu cenário e seus protagonistas. Porto Alegre: Artmed, 2004. 